\title{
Combination of Structural Measures for Flood Prevention in Anyangcheon River Basin, South Korea
}

\author{
Kyunghun Kim ${ }^{1}$, Daegun Han ${ }^{1}$, Deokhwan Kim ${ }^{2}$, Wonjoon Wang ${ }^{1}$, Jaewon Jung ${ }^{1}{ }^{\mathbb{D}}$, \\ Jungwook Kim ${ }^{3}$ and Hung Soo Kim ${ }^{1, *(D)}$ \\ 1 Department of Civil Engineering, Inha University, Incheon 22201, Korea; tgb6111@naver.com (K.K.); \\ eorjs0615@naver.com (D.H.); makelest@naver.com (W.W.); jungjw89@gmail.com (J.J.) \\ 2 Department of Land, Water and Environment Research, Korea Institute of Civil Engineering and Building \\ Technology, Goyang 10223, Korea; kimdeokhwan@kict.re.kr \\ 3 Center for Hydrology and Ecology, Incheon 22201, Korea; love10406@nate.com \\ * Correspondence: sookim@inha.ac.kr; Tel.: +82-10-3441-1038
}

Received: 27 August 2019; Accepted: 24 October 2019; Published: 29 October 2019

\begin{abstract}
Climate change and fast urbanization increased rainfall intensity and runoff discharge. These changes lead to the growing possibility of flood damages. In South Korea, a government established the "Comprehensive Flood Prevention Plan (CFPP)" for each of river basin against flood. The plan is based on the combination of structural measures selected by experienced hydrologists. However, it lacks clear criteria. To solving this problem, this study classifies the structural measures and suggests a combination method, which use relationships between measures, to ensure the objectivity of the process in identifying proper measures. For Anyangcheon river basin, two plans are provided; the first is developed by the study, and the other is by the CFPP. Comparing the two plans, the results show that the combination, selected by proposed method in this study, is economically more feasible compared to CFPP. Therefore, this study expected be useful when selecting and combining structural measures for formulating river basin flood prevention plans.
\end{abstract}

Keywords: flood prevention; structural measures; relationship of measures; combination

\section{Introduction}

Climate change leads to changing precipitation patterns and frequent flood damages. In the Korean peninsula, there has been on increasing frequency of extreme rainfall events including typhoons localized heavy rainfalls that continue for a relatively long-term period [1]. In addition, rapid urbanization causes an increase in runoff, which results to flood, by growth of impermeability layers. This finally causes the growing potential of flood damages. Thus, establishing a flood prevention plan that properly reflects basin characteristics to prevent the flood damages is needed. In Korea, there are ongoing efforts to formulate the plan based on the "Comprehensive Flood Prevention Plan for river Basin" ('CFPPB'). The CFPPB takes an expansive approach for the basin operation by relating the natural and artificial structures (dams, detention pond, flood control reservoir, flood way, etc.) that can restrain flood flows, aiming to strengthen the basin's flood prevention capability (CFPPB for Anyangcheon River Basin, 2005). The CFPPB is composed of four stages in total (survey, analysis, planning, and reporting). Among them, the planning stage is used to select structural measures for a river basin. However, this depends on hydrologists' ability, because of lacking clear criteria for the selection and combination of structural measures. For this reason, the options that the Comprehensive Plan provides for structural measures are in question to serve as an objective foundation. This study aims to raise the objectivity of the process to select the structural measures by applying classification models for flood prevention and a method to combine the relation between the measures. There has 
been active research on selecting flood prevention measures. Chen et al. [2] applied the fuzzy model when selecting the measures. Lee et al. [3] used the analytic hierarchy process and the contingent valuation method to evaluate the measures and get priorities for investment. The developed model suggested the possibility that it could be applied to a variety of areas. However, study show that more verification is needed when it comes to calculating weights through Fuzzy model. Nocker et al. [4] suggested that the Benefit-Cost Analysis Method can be useful for the selection, while Levy et al. [5] applied a Multi-Criteria Decision Support System (MCDSS) to establish emergency measures for flood damages. It has been analyzed that MCDSS facilitates the process of information delivery, increases transparency in decision making, and improves communication among the parties involved in emergency management. Gupta [6] reviewed flood defense measures established after heavy rain damage in Mumbai, India, in 2005. The paper suggested that in order to defend against urban flooding, structural and non-structural measures must be carried out at the same time and, among other things, the importance of the pump system and the water supply system is given in the study. Byeon et al. [7] used the Support Vector Machine to develop decision-making models to classify the measures and applied them to actual basins for evaluation. More verification is needed, but the results of the assessment show that the proposed method is a systematic and objective. Lee et al. [8] applied a range of factors when evaluating the measures and suggesting the priorities for the investment between them. However, the application of the methodology in practice indicated that it was necessary to apply the detailed changes to the characteristics of the area. Based on benefit-cost analysis and probability analysis, Heidari [9] identified the types and scales of the measures to establish an optimal flood prevention plan for a target basin. Yeo et al. [10] evaluated the measures to determine the priorities and optimal measure using the analytic hierarchy process and the utility function by the characteristics of evaluation criteria. Through the research, they developed a model that could evaluate a business on a single, consistent basis. Nevertheless, study show that it was necessary to ensure that the assessment factors and weights fit the purpose of the project to be carried out. Zhou et al. [11] analyzed whether the diversification of the measures has an impact on reducing flood damages Yazdi et al. [12] applied an optimization method based on a simulation when selecting the measures for a basin, and the optimal size of the combination was calculated by applying the Pareto method to compose combinations. The research shows that economically efficient measures can be selected by using the proposed method. Alferi et al. [13] conducted a flood risk assessment throughout the whole Europe area and emphasized the importance of measures that reduce the impact of flooding, rather than those that directly defend against flooding. Rahman et al. [14] assessed the seven defense measures on four criteria to determine their importance. However, there was problem with the weight of each evaluation factors that caused a change of rank. Hino et al. [15] evaluated risk based flood defense alternatives and selected the measure for the target basin using the result of risk analysis. However, the analysis identified significant impacts from two factors (climate change influencing future river flows, and socioeconomic change influencing development in the floodplain). Scionti et al. [16] chose the optimum flood defense measures after assessing those based on the scenario. Taseff et al. [17] suggested a new approach to establish an optimal flood prevention plan under physical and economical limitations.

In previous studies, when selecting candidates for structural flood defense measures to the basin, the alternatives measures were proposed from the existing report or selected in the established flood defense measures. In addition, some studies randomly selected the defenses by the author without criteria. Although there have been studies to establish the optimal size of a combination, there is no method for making combinations. Studies still used establishing all the combinations and comparing the those. This method consumes a lot of time and money for evaluating a lot of union. Therefore, in this study, the candidates of flood defense measures were selected using the characteristics of the basin and vulnerability of flood risk, and the methodology of forming the combination through the relationship between the defense alternatives was proposed. Through this proposed methodology, an objective method was presented in selecting candidates and unlike the previous method, it was able to organize and evaluate the composition of the cooperative plan efficiently. It is believed that this study 
will solve subjectivity in the selection of measures, well as used to develop defense plans through a systematic process.

\section{Analysis on the Current Flood Prevention Plans of South Korea and Other Countries}

Each country formulates flood prevention or mitigation plans. In Korea, the CFPPB for Flood Prevention is established for each basin to prevent damages from flooding. The CFPPB aims to protect the lives and assets of people by properly distributing flood discharge within a basin and enhancing the flood control capacity of prevention structures to minimize flood damages [18]. A total of four stages (survey; analysis, planning, and reporting) constitutes the plan, in which the third stage is a combination of flood measures (Figure 1).

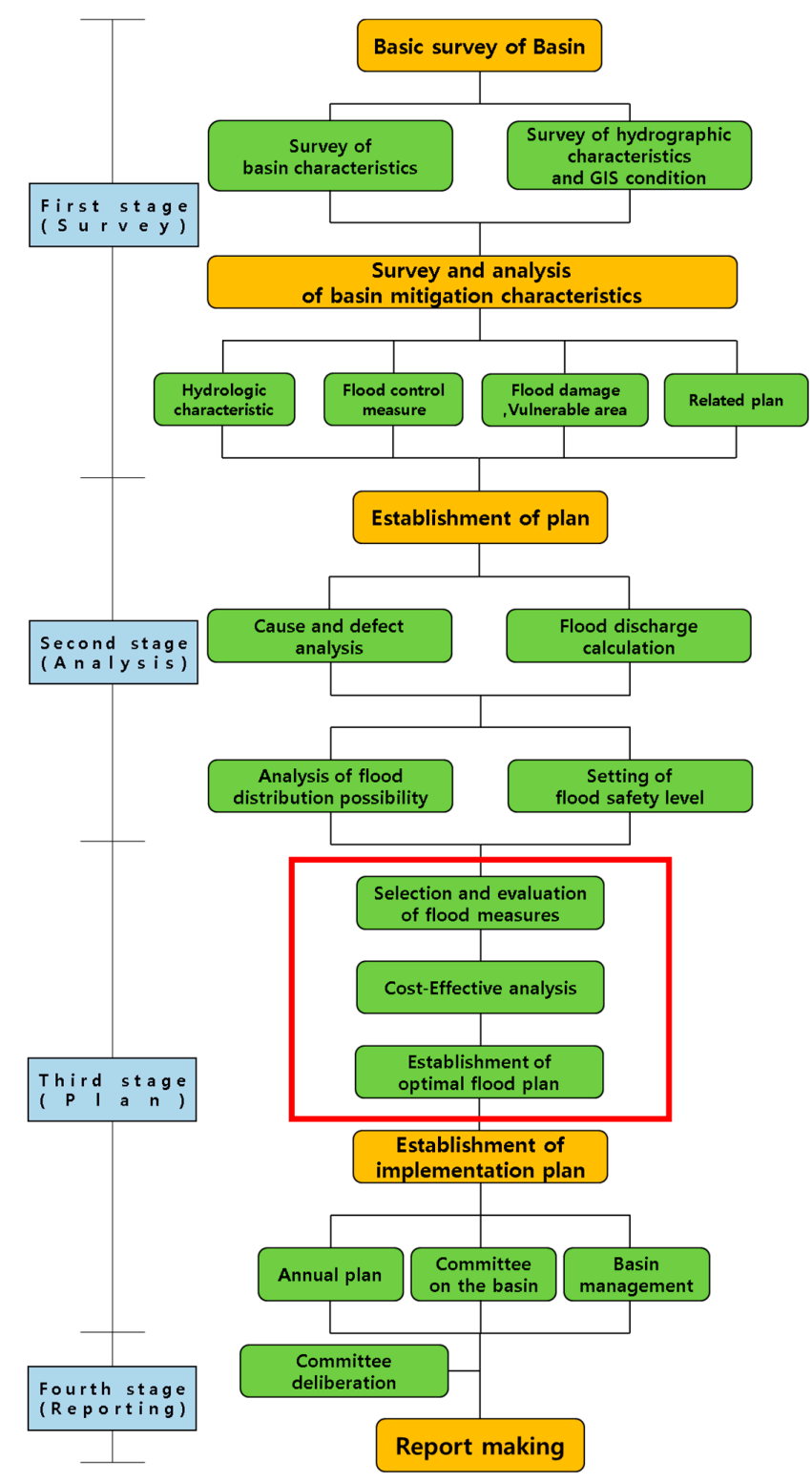

Figure 1. Planning process of the Comprehensive Flood Prevention Plan for River Basin (CFPPB).

During this stage, flood prevention measures are selected, and combinations of them are organized based on a flood prevention scenario provided in stage 2. Economic analysis is used to identify the most economical combination for establishing the plan. However, for the CFPPB, there is no clear standard and the choice is based on the personal capabilities of the engineer. Same problem can be 
found in making combinations of measures. Therefore, if engineer does not have proper competence, plan can be meaningless.

The United States established flood plan in accordance with Executive Order 11988 and 13690. The administration and related agencies formulated feasible flood control plans to prevent damage on a long- and short-term basis, and Executive Order 13690 made revisions regarding the flood level control standards, evaluation methods for the measures, and participation of communities and civic groups [19]. The plan is established through eight stages. Engineers are required to apply as many flood measures as possible to select the most effective alternatives. Major alternatives (e.g., embankments, reservoirs, dams, etc.) are presented by administration and effects are analyzed for long period and short period effects. Then, selected measures are combined. In establishing the combination, the effect is analyzed by increasing the number of measures that add one by one, and selecting the combination that has the greatest effect. In the European Union, flood prevention plans are established based on EU Flood Directive 2007, which is effective from 2007. Accordingly, its member countries are required to conduct a preliminary flood risk evaluation; draw maps of flood areas and flooding risk and finally, formulate the flood risk control plans [20]. The flood measures were presented in three classification criteria (flood hazard, flood exposure, and flood vulnerability) for reference in the selection of flood defense alternatives. After selecting measures, they are assessed in various factors (technical, economic, social, environmental, and et al.) to select the appropriate structural and non-structural factors for the basin to improve the flood defense capability of the basin. In Japan, the central government established a masterplan for flood control and the local governments, and designated agencies formulate subplans to prevent flood damages. In 2003, the masterplan was revised to add measures for handling urban flood issues. It was required to set a target year and predict the urbanization level in a basin for the year to prepare countermeasures for the forecasted flood [21]. When selecting a set of flood prevention measures, Japan organizes several combinations of structural and non-structural measures and finally identifies the one that is the most efficient from an economic perspective. As such, each country has selected the most effective measures to defend against flood and commonly, it specifies the use of a combination of structural and non-structural measures. However, in the selecting, Europe and Japan offer measures using classification results, while in the U. S and Korea, engineers are required to make their inferences without references. It also increases efficiency by allowing the selection of measures based on the classification results because it does not require the assessment of all defense alternatives and makes the measures judging with same criteria. Therefore, it may be desirable to classify and present measures to engineers in selecting the required flood defense alternative for the basin, like Europe and Japan. It was analyzed since not all countries can provide clear criteria for the combination, thus a methodology needed to efficiently form the combination was needed.

\section{Development of Classification Model and Combination of Structural Flood Prevention Measures}

\subsection{Classification of Structural Flood Prevention Measures}

Classification refers to a division of things into similar groups or types. It is widely used for research because it allows the same analysis method to be applied to subjects that are divided, which belong to the same group. Flood prevention measures have long been classified with diverse criteria. Penning-Rowseel and Peerbolte [22] classified measures not only by its structural/non-structural criteria, but also according to characteristics of the measures. Groups were again divided into three groups (water control measure, land use control measure, \& financial relief and loss reduction) depending on their defensive purpose. Petry [23] classified measures by scale to which they can protect. The measures are grouped into two categories, one for those that can protect an extensive area and the other for the intensive area. In Korea's CFPPB, flood measures are classified only to two groups by simply depending on whether they are structural and non-structural. According to Parker [24] the measures could be classified into a "flood hazard reduction group" or "flood vulnerability reduction group". Olfer and Schanze [25] used two classification criteria to divide structural flood prevention 
measures. For the first classification, the measures were divided into "Measurement" and "Instrument" groups. The measurement group includes structural measures that have long been used for flood prevention and have a direct impact by themselves. The instrument group includes measures to enhance the awareness and preparatory capability for risks that lead to damage prevention effect. The second classification was made by function that each of the measures is secure for the measurement and instrument groups. Measures under the measurement group were divided into to three subgroups (adaptation, control, and retreat), and those under the instrument group were divided into to four subgroups (regulation, stimulation, communication, and compensation). A total of 20 measures were subject to the classification. The Center for Research on Unexpected Events (CRUE) (2008) divided the measures for the first classification into structural and non-structural measures and obtained the second classification through their function [26]. For the third classification, the measures were divided again through the function to classify the structural and non-structural flood prevention measures into 17 groups. Byeon et al. [7] used three classification criteria to group nine structural flood measures. They used the support vector machine (SVM) method and developed a decision-making tree for the classification. In the first step, the measures for the target area were divided for water retention, water retarding, and low-land zones. In the second step, classification was made by the criteria of downstream flood discharge, water level reduction, and inundation. For the third step, the measures were divided into nine groups based on their flood control effect and location. Korea's River Design Criteria (2009) classified flood prevention measures into seven groups in total based on their function: river inundation control, increase of flood conveyance ability, decrease of water level, stabilization of riverbed, decrease of peak discharge, internal drainage, and defense of coastal inundation [27]. Heidari [9] classified flood prevention measures into four functions (reducing discharge, reducing stage, reducing existing damage susceptibility, reducing future damage susceptibility). In the countries mentioned in Section 2, as well as in the above studies, flood structural defense measures were classified through various classification criteria. We identified the criteria based on previous studies to classify the measures that include the structural or non-structural measures the scale of prevention, function, location for installation, and target of control. The survey data and definition of flood measures that we obtained from the previous study, papers, and reports have provided the foundation for this study to develop a model that classifies structural flood prevention measures.

\subsection{Development of Classification Model to Select Flood Measures}

In this study, a classification model for structural flood defense measures was developed to solve the problem in selecting candidates in the CFPPB. Prior to the development, the CFPPB was investigated from 2005 to identify the structural measures that have been widely used in Korea. Through the investigated data, we found eight structural flood measures (increasing the storage capacity of multipurpose dam, flood way, drainage pump station, detention pond, increasing of reservoir capacity, construction and enlargement of levee, washland, improvement of river channel).

We chose classification criteria to categorize the eight measures selected. In selecting the criteria, the basic data investigated in Section 3.1 were used, and we picked two classification criteria. The first classification criterion was the installable area of the structural flood defense measure. The area is specified into three areas (mountainous, rural, and urban), which are distinguished by the CFPPB. Structural flood defense measures have their own characteristic and functions; thereby, the regional characteristics that can be installed are defined. Multipurpose dams, for example, are structural defense measures that store water in the upstream of rivers to prevent flood damage of the downstream area. Therefore, for installation of the dams, it must be in the upper reaches of river and have a space for water: thus, it can only be constructed in mountainous areas. In addition, because various characteristics of the target area are analyzed before the selection of measures, we could an easily identify which region belongs to one of the three areas. And then, if we have the classification results according to the installation area, we could an efficiently find the viable structural flood measures. 
As the second criterion, the function of structural measures were chosen. The functions are largely divided into three categories and are the same as below:

(1) Function for preventing overflow Directly preventing water from flowing over a river channel.

(2) Function for diversification Distributing water to prevent it from flowing over a river channel.

(3) Function for detention Storing rainwater on a temporary basis to prevent water from flowing over a river channel.

Flood risk analysis is performed with regional characteristics when flood defense measures are selected for the target area. The flood risks analysis identifies the area's vulnerability to flooding and these factors can be used to check what functions are needed. For example, if a risk analysis identifies a lack of discharge capacity in the target basin, it may be needed to increase the capacity of the stream or distribute the flow to prevent flooding. Therefore, it is necessary for engineers to search for structural measures that have either two functions or perform one of them. If, as like in this study, there are some suggestions for flood defense measures according to their functions, engineers will be able to easily select measures. This advantage has led many reports and studies to use the function of the measure as a key classification criterion. In terms of classification, flooding defense measures were selected overlapping in each step. The classification model was developed by applying the selected classification criteria to eight structural flood defense measures. All measures were categorized into eight groups (Figure 2).

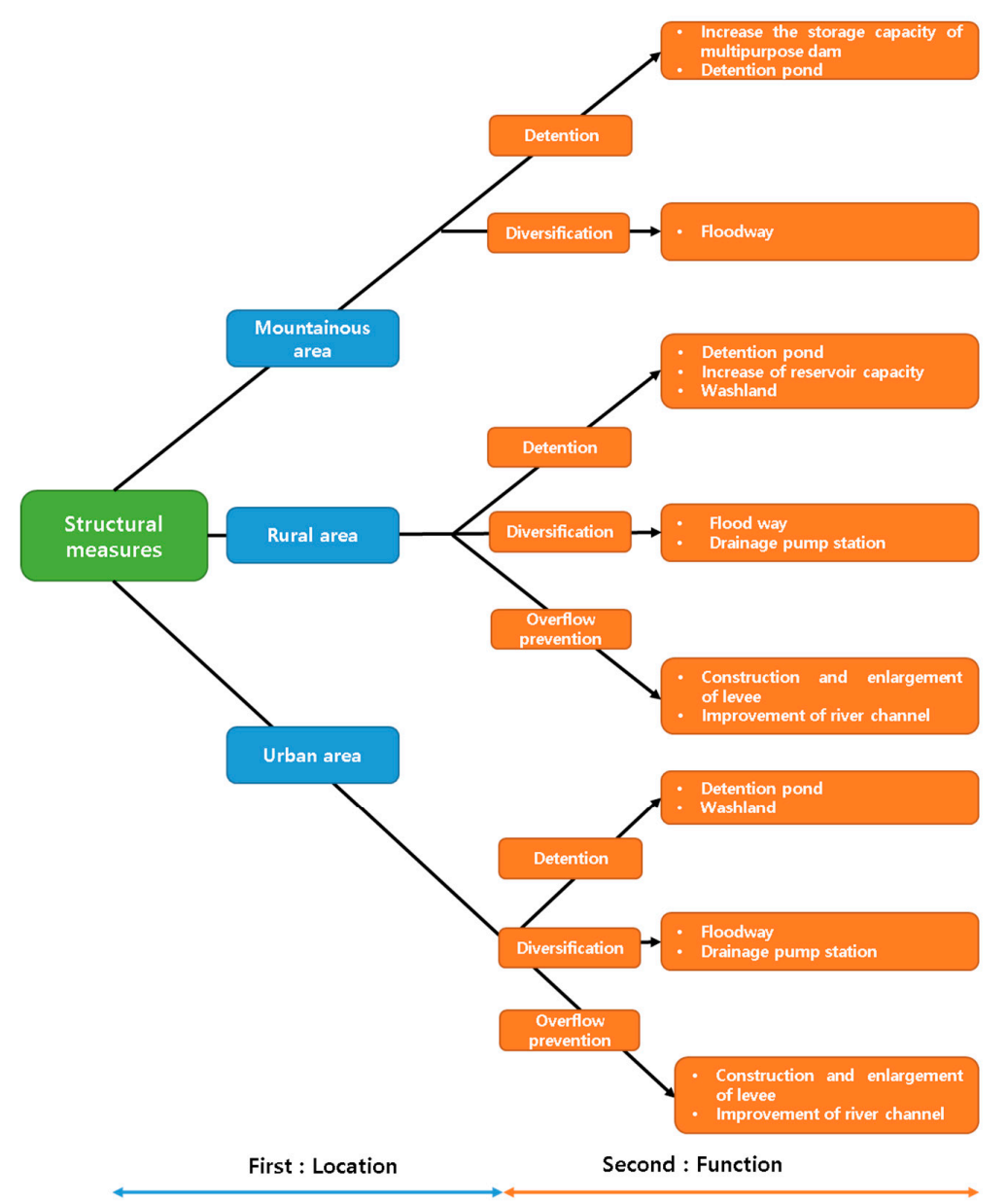

Figure 2. Classification model of structural measures. 


\subsection{Relationship Between Flood Measures and Development of Their Combination}

The optimal flood prevention plan can be a set of a single measure or two or more measures. When the plan constitutes several measures, it is required to find a relation between them. Ref. [28] classified the relations into an "independent proposal" and a "dependent proposal" depending on whether the measures work independently or dependently for each other (Figure 3). When applied to a combination of measures, this classification helps in determining whether or not:

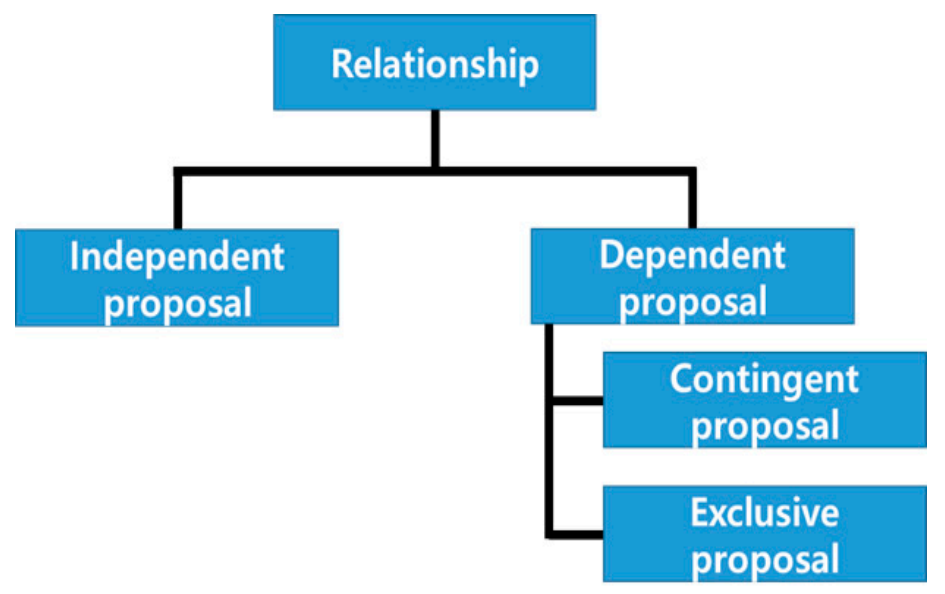

Figure 3. Relationship between flood prevention measures.

(1) Independent proposal

An independent proposal refers to the relationship between flood prevention measures that do not have any impact on the others when selected.

(2) Dependent proposal

Dependent proposals include "exclusive proposal", where flood measures are in an exclusionary relationship, and "contingent proposal", where one measure is in a relationship with the other supportive measures. When the selection of a measure leads to a result that the other measure cannot be implemented, the two measures are considered in an exclusionary relationship. Measures of an exclusive proposal include those with the same purpose. In this case, it is not appropriate to implement both of the measures because they will produce the same result and thus, it is ideal to compare them and select one with higher efficiency. For a contingent proposal, the selection of a measure automatically brings its supportive measures. Take the example of the contingent proposal with a project for the construction of consecutive levees. Missing one levee, will result in the entire project making meaningless. Other examples include the construction of levees and drain pump stations.

To select the optimal flood measure combination, it is the traditional method that makes all possible combinations and compares them with the criteria [29,30]. However, this method requires in a number of analysis periods and costs. Suppose that there are $\mathrm{N}$ installable flood defense measures that have been chosen. The number of combinations that may appear for $\mathrm{N}$ measures is $2^{N}$. If the number of measures is increased to $\mathrm{N}+\mathrm{K}$, the total of combination is $2^{N+K}$ which is $2^{K}$ times. This results in doubling the time and cost of the analysis. However, in practice, some of the combinations are composed of flood measures that cannot be implemented in the same time, or some are missing which needs to performed together. Analyzing these combinations is a waste of time and money. If we use the relationship between measures, we can exclude impracticable combinations. For instance, if the two measures that have contingent relationship are not in the same combination, the combination has no effect in preventing the flood damage. In another example, if there is exclusive relationship in the combination, we can recognize the impossibility of the group. In both cases, engineers can reduce the total number of combinations before the analysis. Take the example of the assumption that four 
options $\left(m_{1}, m_{2}, m_{3}, m_{4}\right)$ are selected as the feasible flood measures and have relationship shown in Table 1.

Table 1. Benefit and relationship of flood measures.

\begin{tabular}{ccc}
\hline Measure & Benefit (USD Thousand) & Relationship \\
\hline$m_{1}$ & 25 & Exclusive with $m_{2}$ \\
$m_{2}$ & 17 & Exclusive with $m_{1}$ \\
$m_{3}$ & 7 & Contingent with $m_{1}$ \\
$m_{4}$ & 12 & Independent proposal \\
\hline
\end{tabular}

The four flood measures can compose up to $2^{4}(16)$ combinations in total. However, only seven combinations are feasible when they are evaluated with the relationship between the measures (Table 2). Without the relationship being applied, the evaluation needs to be made for each of the 16 combinations. Unlike, when the relationship is considered, the number of subjects for evaluation decreases to save the time and cost for analysis. Evaluation is made to have benefits as the only criteria for the seven feasible combinations, and $C_{14}$ is identified as the optimal combination of the flood measures. In addition, the method that uses relationship was applied in the CFPPB of 2007, and its applicability was verified (Table 2). Other fields of the study have utilized methods that use relationships to evaluate the combinations [31,32].

Table 2. Determination of proper combinations using relationship.

\begin{tabular}{ccccccccc}
\hline \multirow{2}{*}{ Comb } & \multicolumn{5}{c}{ Measures } & \begin{tabular}{c} 
Benefit \\
(USD \\
\cline { 2 - 4 } Thousand)
\end{tabular} & Feasibility & Impossible Reason \\
\cline { 2 - 5 } $\mathrm{C}_{1}$ & $\mathrm{X}$ & $\mathrm{X}$ & $\mathrm{X}$ & $\mathrm{X}$ & 0 & $\mathrm{X}$ & No effect \\
$C_{2}$ & $\mathrm{O}$ & $\mathrm{X}$ & $\mathrm{X}$ & $\mathrm{X}$ & 25 & $\mathrm{O}$ & \\
$C_{3}$ & $\mathrm{X}$ & $\mathrm{O}$ & $\mathrm{X}$ & $\mathrm{X}$ & 17 & $\mathrm{O}$ & Contingent proposal $\left(m_{1}, m_{3}\right)$ \\
$C_{4}$ & $\mathrm{X}$ & $\mathrm{X}$ & $\mathrm{O}$ & $\mathrm{X}$ & 7 & $\mathrm{X}$ & \\
$C_{5}$ & $\mathrm{X}$ & $\mathrm{X}$ & $\mathrm{X}$ & $\mathrm{O}$ & 12 & $\mathrm{O}$ & \\
$C_{6}$ & $\mathrm{O}$ & $\mathrm{O}$ & $\mathrm{X}$ & $\mathrm{X}$ & 42 & $\mathrm{X}$ & Exclusive proposal $\left(m_{1}, m_{2}\right)$ \\
$C_{7}$ & $\mathrm{O}$ & $\mathrm{X}$ & $\mathrm{O}$ & $\mathrm{X}$ & 32 & $\mathrm{O}$ & \\
$C_{8}$ & $\mathrm{O}$ & $\mathrm{X}$ & $\mathrm{X}$ & $\mathrm{O}$ & 37 & $\mathrm{O}$ & \\
$C_{9}$ & $\mathrm{X}$ & $\mathrm{O}$ & $\mathrm{X}$ & $\mathrm{O}$ & 29 & $\mathrm{O}$ & \\
$C_{10}$ & $\mathrm{X}$ & $\mathrm{O}$ & $\mathrm{O}$ & $\mathrm{X}$ & 24 & $\mathrm{X}$ & Contingent proposal $\left(m_{1}, m_{3}\right)$ \\
$C_{11}$ & $\mathrm{X}$ & $\mathrm{X}$ & $\mathrm{O}$ & $\mathrm{O}$ & 19 & $\mathrm{X}$ & Contingent proposal $\left(m_{1}, m_{3}\right)$ \\
$C_{12}$ & $\mathrm{O}$ & $\mathrm{O}$ & $\mathrm{O}$ & $\mathrm{X}$ & 49 & $\mathrm{X}$ & Exclusive proposal $\left(m_{1}, m_{2}\right)$ \\
$C_{13}$ & $\mathrm{O}$ & $\mathrm{O}$ & $\mathrm{X}$ & $\mathrm{O}$ & 54 & $\mathrm{X}$ & Exclusive proposal $\left(m_{1}, m_{2}\right)$ \\
$C_{14}$ & $\mathrm{O}$ & $\mathrm{X}$ & $\mathrm{O}$ & $\mathrm{O}$ & 44 & $\mathrm{O}$ & \\
$C_{15}$ & $\mathrm{X}$ & $\mathrm{O}$ & $\mathrm{O}$ & $\mathrm{O}$ & 36 & $\mathrm{X}$ & Contingent proposal $\left(m_{1}, m_{3}\right)$ \\
$C_{16}$ & $\mathrm{O}$ & $\mathrm{O}$ & $\mathrm{O}$ & $\mathrm{O}$ & 61 & $\mathrm{X}$ & Exclusive proposal $\left(m_{1}, m_{2}\right)$ \\
\hline
\end{tabular}

\section{Selection of Flood Prevention Measures for Anyangcheon River Basin}

\subsection{Target Area}

In this study, the Anyangcheon river basin is selected as the target area. It is a stream of middle scale with $286 \mathrm{~km}^{2}$ of basin area, $32.5 \mathrm{~km}$ of river in length, and $8.8 \mathrm{~km}$ of average in width. It also stretches over the metropolitan areas of South Korea, Seoul, and Gyeonggi-do province. For the basin's geographical characteristics, the downstream covers the urban area and, along with the middle and upper stream residential and downtowns, are concentrated. The cost that arises from flood damages in the Anyangcheon river basin reached KRW 250.4 billion from 1971 to 2016, with the annual average cost of about KRW 5.44 billion. In the basin, the study focuses on the main Anyangcheon stream and Mokgamcheon stream in which urban area is located and flood vulnerability is high (Figure 4). 


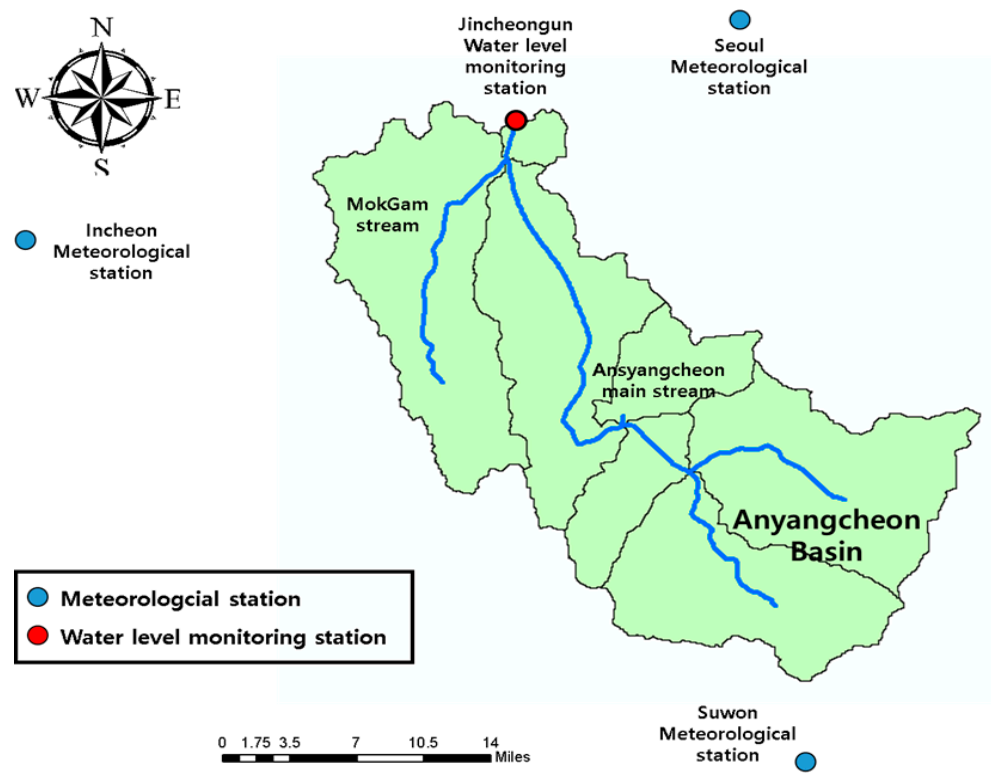

Figure 4. Anyangcheon basin and peripheral observation stations.

\subsection{Flood Risk Analysis Using the Inumdation Map and Potential Flood Damage (PFD)}

The study drew an inundation map and then used the potential flood damage (PFD) to determine whether the installation of flood measures is required. Also, flood-prone areas at the main Anyangcheon stream and Mokgamcheon stream are identified.

In the Comprehensive Plan, a design frequency is set as 200 years and 50 years of flood discharge for the main Anyangcheon stream and Mokgamcheon stream, respectively, Therefore, the study used the Frequency Analysis of Rainfall Data Program (FARD) to calculate probability rainfalls for the frequencies of 50 years and 200 years. The obtained probability rainfalls were applied to the main Anyangcheon stream and Mokgamcheon stream modeled using the hydrologic engineering center-hydrologic modeling system (HEC-HMS) to calculate the flood discharge by frequency for each stream. In addition, the study obtained flood elevations using the flood discharges calculated using hydrologic engineering center-river analysis system (HEC-RAS). The elevation value for each of the stream sections was applied to the digital elevation model (DEM) to obtain the inundation map (Figure 5). 


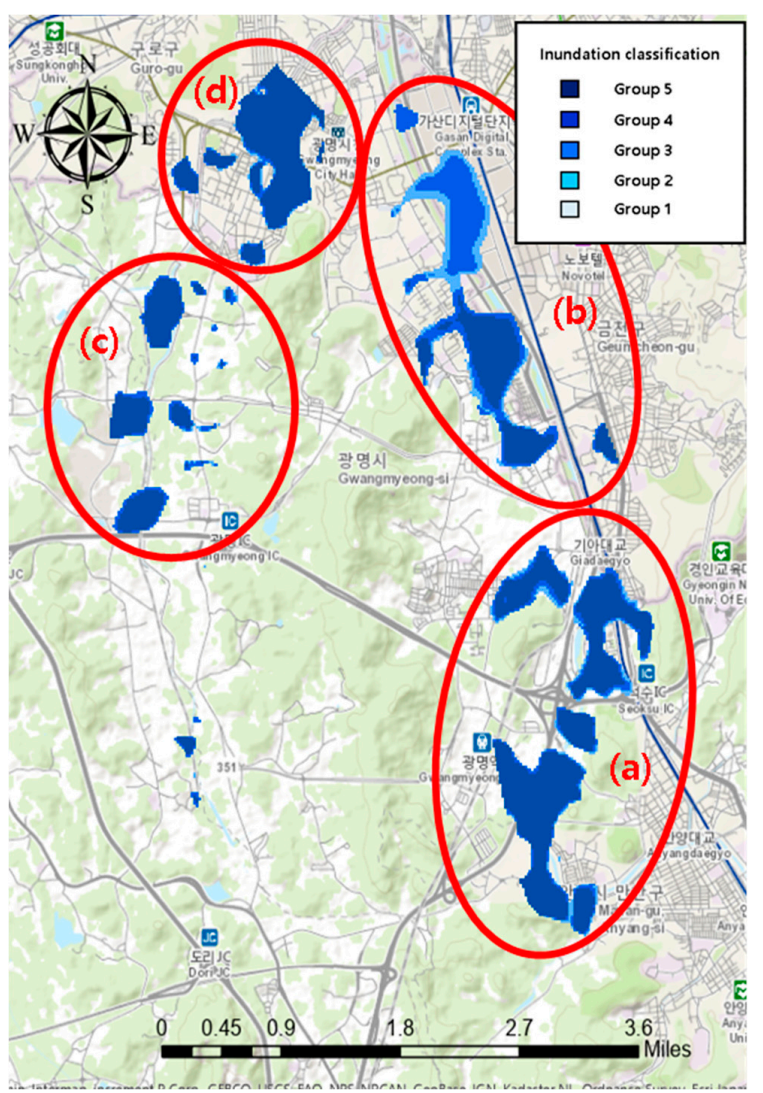

Figure 5. Inundation zone of two streams: each stream showed two inundation zones (Anyangcheon main stream: $(\mathbf{a}, \mathbf{b}) /$ Mokgamcheon stream: $(\mathbf{c}, \mathbf{d}))$; Each zone is consist of 5 inundation groups according to water level (h) (Group 1: $0 \mathrm{~m} \leq \mathrm{h} \leq 0.5 \mathrm{~m}$, Group 2: $0.5 \mathrm{~m}<\mathrm{h} \leq 1.0 \mathrm{~m}$, Group 3: $1.0 \mathrm{~m}<\mathrm{h} \leq 2.0 \mathrm{~m}$, Group 4: $2.0 \mathrm{~m}<\mathrm{h} \leq 3.0 \mathrm{~m}$, Group 5: $3.0 \mathrm{~m}<\mathrm{h}$ ).

In both of the streams, two large inundated zones occurred. Figure 5a for the main Anyangcheon stream, because of the vacant lot around the stream, warehouses and facilities on the banks behind the vacant lot were not damaged by flood. However, the urban area, Figure $5 \mathrm{~b}$ is located in both sides of the river. Therefore, flooding would bring about significant damages. In Figure $5 \mathrm{c}$ rural area and Figure $5 \mathrm{~d}$ urban areas for the Mokgamcheon stream, it is expected to experience damages both to livelihood and crops.

The potential flood damage (PFD) was calculated to obtain PFD grades and identify whether a structural prevention measure is necessary for the inundated areas found in the inundation map. The PFD is divided into eight grades in total, among which grades A, B, D, and E are those that need structural flood measures (Table 3). Figure 6 shows the PFD calculation results. For the grade classification for the main Anyangcheon stream, Figure 6a,b were graded as A, which indicates the necessity to implement structural flood measures. In the case of Mokgamcheon stream, Figure $6 c, d$ ranged from grade A to $\mathrm{F}$. This indicates the necessity of structural flood prevention measures for the area. 
Table 3. The direction of flood measure by Potential Flood Damage (PFD) class.

\begin{tabular}{|c|c|}
\hline Class & Directions for Flood Measures \\
\hline $\mathrm{A}$ & $\begin{array}{l}\text { Areas that require flood control improvement with more focus on } \\
\text { structural measures }\end{array}$ \\
\hline B & $\begin{array}{l}\text { Areas that also require flood control improvement but need to give more } \\
\text { consideration on local conditions than A when seeking for structural } \\
\text { measures }\end{array}$ \\
\hline $\mathrm{C}$ & $\begin{array}{c}\text { Areas that require the installation of flood measures, but need to give } \\
\text { more consideration on non-structural measures and local conditions } \\
\text { than structural measures when seeking for flood control and safety } \\
\text { measures }\end{array}$ \\
\hline $\mathrm{D}$ & $\begin{array}{l}\text { Areas that require the preparation of measures that reflect the local } \\
\text { conditions, that is, by aiming at reducing inundation at a downstream } \\
\text { from its upper stream }\end{array}$ \\
\hline $\mathrm{E}$ & $\begin{array}{c}\text { Areas that require the installation of flood prevention facilities and } \\
\text { rising of the flood safety level, but need both structural and } \\
\text { non-structural measures }\end{array}$ \\
\hline $\mathrm{F}$ & $\begin{array}{l}\text { Areas that require flood prevention facilities but need to seek for } \\
\text { non-structural measures }\end{array}$ \\
\hline G & $\begin{array}{l}\text { Areas that secure sufficient flood prevention facilities, and, thus, need to } \\
\text { give more focus on non-structural measures }\end{array}$ \\
\hline $\mathrm{H}$ & $\begin{array}{c}\text { Areas that require measures, which can be implemented in harmony } \\
\text { with environmental friendly projects }\end{array}$ \\
\hline
\end{tabular}

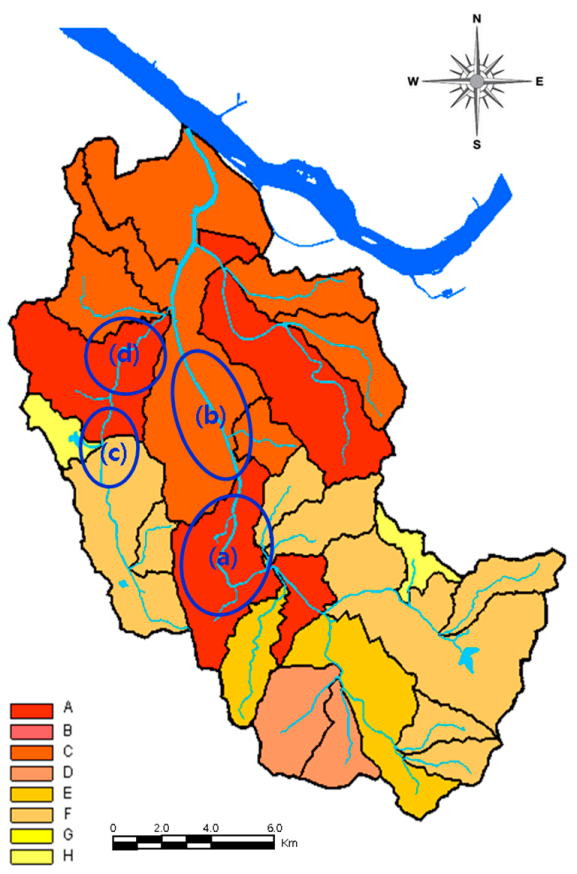

Figure 6. Potential flood damage (PFD) result of Anyangcheon basin (Anyancheon main stream: $(\mathbf{a}, \mathbf{b})$ /Mokgamcheon stream: $(\mathbf{c}, \mathbf{d}))$; Each area is the same as the one shown in Figure 5.

\subsection{Selection of Feasible Flood Measures and Their Combination}

In Sections 4.1 and 4.2 , the study selected feasible flood prevention measures by applying the classification model developed for the areas that were identified necessary for the measures. In the case of the Anyancheon main stream, only Improvement of river channel $\left(A_{1}\right)$ is chosen. Improvement of river channel $\left(B_{1}\right)$, Washland $\left(B_{2}\right)$ and Increasing of reservoir capacity $\left(B_{3}\right)$ is selected about the 
Mokgam stream. Construction costs and benefits were calculated for the selected measures with a method to estimate the costs and the multidimensional flood damage analysis. The results are shown in Table 4.

Table 4. Construction cost, benefit, and Benefit/Cost (B/C) of feasible flood measures.

\begin{tabular}{ccccc}
\hline Target Stream & Flood Measure & $\begin{array}{c}\text { Construction Cost } \\
\text { (KRW Million) }\end{array}$ & $\begin{array}{c}\text { Benefit (KRW } \\
\text { Million) }\end{array}$ & Benefit/Cost \\
\hline $\begin{array}{c}\text { Anyangcheon main } \\
\text { stream }\end{array}$ & $\begin{array}{c}\text { Improvement of river } \\
\text { channel }\left(A_{1}\right)\end{array}$ & $47,572.0$ & $134,001.0$ & 2.82 \\
Improvement of river & channel $\left(B_{1}\right)$ & $38,294.2$ & $39,757.0$ & 1.04 \\
Mokgam stream & $\begin{array}{c}\text { Washland }\left(B_{2}\right) \\
\text { Increasing of reservoir } \\
\text { capacity }\left(B_{3}\right)\end{array}$ & $79,109.2$ & $129,830.9$ & 1.64 \\
& 9502.0 & $14,983.1$ & 1.58 \\
\hline
\end{tabular}

Based on the calculated results, it was found that the cost of installing washland in Mokgam stream was the most expensive, due to costly land purchases for the construction. In terms of benefits, the largest amount was calculated for improvement of river channel in Anyangcheon main stream. As mentioned above, the Anyangcheon main stream contains many elements of personal property compared to other area, because both sides of the river are made up of residential areas. Therefore, the benefits are thought to be significant because it prevents damage to these properties through river channel improvement. In view of the efficiency of the investment, the improvement of river channel of Anyangcheon main stream showed the greatest efficiency, and that of the Mokgam stream gave the least efficiency. These greater benefits in terms of investment costs (all Benefit/Cost $(B / C)$ ratio is over than 1.0).

Prior to organizing combinations of the four flood measures, the study identified the relationship between them. The river restoration works conducted for the main Anyangcheon stream do not have an influence on structural measures in the Mokgamcheon stream. Therefore, it has an independent relationship with the rest of the measures. The river restoration work done for Mokgamcheon stream does not affect the other two measures, which means it is also independent with the others. On the contrary, the construction of washlands and raised reservoir levee have the same function that makes them in "exclusive proposal". Based on these results, the study organized combinations and selected the optimum based on the Benefit-Cost (B-C).

As a result of calculating and evaluating the combinations (Table 5), it was found that the combination made with the river restoration for the main Anyangcheon stream and the river restoration and raised reservoir levee for the Mokgamcheon stream had the highest value of B-C. Therefore, C6 was selected as the optimal combination.

Table 5. Combination of viable flood measures.

\begin{tabular}{|c|c|c|c|c|c|c|}
\hline \multirow{2}{*}{ Combination } & \multicolumn{4}{|c|}{ Measure } & \multirow{2}{*}{$\begin{array}{c}\text { B-C (KRW } \\
\text { Million) }\end{array}$} & \multirow{2}{*}{ Impossible Reason } \\
\hline & $A_{1}$ & $B_{1}$ & $B_{2}$ & $B_{3}$ & & \\
\hline$C_{1}$ & $\mathrm{o}$ & $x$ & $x$ & $x$ & - & No effect \\
\hline$C_{2}$ & $\mathrm{o}$ & $\mathrm{o}$ & $x$ & $x$ & 87,892 & \\
\hline$C_{3}$ & $\mathrm{o}$ & $x$ & $\mathrm{o}$ & $x$ & 137,151 & \\
\hline $\mathrm{C}_{4}$ & $\mathrm{o}$ & $x$ & $x$ & $\mathrm{o}$ & 91,910 & \\
\hline $\mathrm{C}_{5}$ & $\mathrm{o}$ & $\mathrm{o}$ & $\mathrm{o}$ & $x$ & 138,614 & \\
\hline $\mathrm{C}_{6}$ & $\mathrm{o}$ & $\mathrm{o}$ & $x$ & $\mathrm{o}$ & 93,373 & \\
\hline$C_{7}$ & $\mathrm{o}$ & $x$ & o & $\mathrm{o}$ & - & Exclusive proposal $\left(B_{2}, B_{3}\right)$ \\
\hline$C_{8}$ & $\mathrm{o}$ & $\mathrm{o}$ & $\mathrm{o}$ & $\mathrm{o}$ & - & Exclusive proposal $\left(B_{2}, B_{3}\right)$ \\
\hline
\end{tabular}




\subsection{Comparison with the Comprehensive Flood Prevention Plan}

To verify the practicability, a comparison was conducted between the combination of the study and that of the optimal flood measures that were set in 2005 for the Anyangcheon stream (see Table 6).

Table 6. Comparison of $\mathrm{B} / \mathrm{C}$ ratios for the selected structural measures by the Comprehensive Flood Prevention Plan for river Basin (CFPPB) and Combination.

\begin{tabular}{|c|c|c|c|c|}
\hline Target Stream & Measures & $\begin{array}{l}\text { Construction Cost } \\
\text { (KRW Million) }\end{array}$ & $\begin{array}{l}\text { Benefit (KRW } \\
\text { Million) }\end{array}$ & $\mathrm{B} / \mathrm{C}$ \\
\hline Hagui & Reservoir, floodgate & 2952 & 40,738 & 13.8 \\
\hline Siheung & $\begin{array}{l}\text { Improvement of river } \\
\text { channel }\end{array}$ & 2305 & 13,046 & 5.7 \\
\hline Mokgam & Floodway & 211,060 & 230,055 & 1.1 \\
\hline Oryu & $\begin{array}{l}\text { Expansion of Drainage } \\
\text { pump station }\end{array}$ & 41,366 & 59,153 & 1.4 \\
\hline Dorim & Underground Floodway & 64,758 & 66,060 & 1.1 \\
\hline \multirow[t]{2}{*}{ Daebang } & $\begin{array}{c}\text { Improvement of river } \\
\text { channel }\end{array}$ & 4803 & 23,247 & 4.8 \\
\hline & lbination & 327,244 & 432,299 & 1.3 \\
\hline
\end{tabular}

The CFPPB for the Anyangcheon stream aims to reduce the flood discharge in the main stream by installing a combination made with the six flood measures. Among them, to decrease the flood discharge, a floodway was installed from the Mokgamcheon stream to the main stream of the Hangang River. However, because this measure requires the floodway to be installed from the near basin outside the Anyangcheon stream, the construction costs will be higher (Table 6).

The study compared the two combinations. However, as the two have different areal extents for the cost-benefit calculation, it was not possible to compare them directly. Therefore, out of the optimal combinations of the Comprehensive Plan, we screened out the flood measures that were established for the streams similar to the study's target areas and conducted the comparison analysis (Table 7). The Haguicheon and Dorimcheon streams were selected to compare the main stream of Anyangcheon for the flood measures, which includes the installation of reservoirs, sluice gates, and underground floodways. For the Mokgamcheon stream, because the Comprehensive Plan also had the same stream as the target, a comparison was made for the floodway. However, the comparison for the benefits of the floodway was not possible because it includes the benefit to reduce flood damages in the other basin where the floodway is installed. Therefore, among the prevention measures established for the Mokgamcheon stream, the installation of a regulating reservoir and a drain pump station was selected for the comparison because they had the same scale as the target of this study.

Table 7. Comparative optimal combination.

\begin{tabular}{ccccc}
\hline Target Stream & Measures & $\begin{array}{c}\text { Construction Cost } \\
\text { (KRW) }\end{array}$ & $\begin{array}{c}\text { Benefit (KRW } \\
\text { Million) }\end{array}$ & B/C \\
\hline \multirow{2}{*}{ Mokgamcheon } & Flood control reservoir, & 196,922 & 157,537 & 0.8 \\
Hagui & Drain pump station & 2952 & 40,738 & 13.8 \\
Dorim & Reservoir, floodgate & 64,758 & 66,060 & 1.1 \\
& Underground Floodway & 264,632 & 269,509 & 1.0 \\
\hline
\end{tabular}

$\mathrm{B} / \mathrm{C}$ and B-C were calculated to conduct the comparison with the combination of the study (Table 8). As a result, for B/C, the study's combination had 1.8, which is 1.8 times higher than that of the Comprehensive Plan. This indicates that the study's combination is more cost-effective. The comparison of B-C of the two combinations suggested that both led to benefiting greater than the spent. 
It was also found that the study combination brought higher benefit and less expenses. Therefore, it was verified that the combination of the study is more economical than that of the Comprehensive Plan.

Table 8. Comparison results of two methods.

\begin{tabular}{ccccc}
\hline Combination & $\begin{array}{c}\text { Construction Cost (KRW } \\
\text { Million) }\end{array}$ & $\begin{array}{c}\text { Benefit (KRW } \\
\text { Million) }\end{array}$ & $\begin{array}{c}\text { B-C (KRW } \\
\text { Million) }\end{array}$ & B/C \\
\hline $\begin{array}{c}\text { Study }\left(C_{5}\right) \\
\begin{array}{c}\text { Comprehensive } \\
\text { flood control } \\
\text { management plan } \\
\text { Difference }\end{array}\end{array}$ & 164,975 & 303,588 & 138,614 & 1.84 \\
\hline
\end{tabular}

\section{Conclusions}

In this study, two methodologies were proposed to solve the problem for no clear criteria in selecting structural flood defense measures. Structural flood defense measures classification model was developed using two classification criteria (Area, Function). By using the relationship between measures (independent, dependent (contingent, exclusive)), combination methodology to eliminate impossible combinations was suggested. These new methodologies were applied to the Anyangcheon basin, where residential areas are concentrated and the most economical combinations was selected. In order to confirm the appropriateness of the best combination, the existing flood defenses were compared with economic factors and the results of this study showed better indicators. The classification model helped in selecting candidates by utilizing the analysis results (characteristics of basin, flood risk analysis) performed before the selecting procedure. It also eliminates the inefficiency that engineers have to evaluate all structural flood defense measures in selection process. The relationship between measures has increased the efficiency of the analysis by removing the impracticable proposals compared to the existing method. However, it is necessary to define the classification model and relationships between measures by reflecting the opinions of more experts. If these processes are passed and then distributed to the experts in practice, those can be used as a reference as an alternative procedure or criterion in the choice of flood measure. While existing criteria have ambiguity, those include clear criteria can reduce confusion among practitioners and reliance on individual capabilities. This method gives the clear criteria. So it is believed that even less experienced engineers can select effective flood defense measures for the target basin.

However, in the study, only eight structural flood defense measures were used to develop the model. Since only a small number of defense measures have been used, if the model is applied to all the basins in the country, uniformed flood plains can be established. Therefore, it is suggested that more types of structural defense measures would be applied in the future studies. Also, one problem that can arise is that the engineer responsible for selection could miss define the relationship between measures. As suggested by Lee, the definition is not clear in the actual application. Thus, it is necessary to use survey or any other tools. To integrate the opinions of various researchers to clearly define the relationship between measures. Lastly, the analysis was performed with only one economic factor in selecting and comparing the optimal combination. Several studies have incorporated many indicators to compare the combinations. However, these studies have encountered problems with the appropriateness of the assessment indicators and drawback with the weight of each indicator, all of which can change the result. Many researchers are using different indicators and weights. Therefore, in Korea, the government still make judgements on economic factor in practice. However, since defense measures affect not only economics, but also the environment, ecosystems, and policies, it is the right way to evaluate the measures. Therefore, we are studying with them about the assessment indicators and weight calculation method, which is suitable. There is another reason why we only use economic factors. In the case of a comparative combination to confirm the validity of the proposed methodology, only the economic factors were analysis so that only those were possible for the comparator. So, in 
the future research, we will choose other basins and evaluate combinations with many assessment indicators. Despite these problems, the methodology of this study helps to establish flood defense measures in an objectified way, not in an engineer's personal capacity. It also allows engineers to conduct analysis more efficiency when making the flood plain. Concept of "relationship between defense alternatives" was used for selecting flood defense measures. If this concept is clearly defined and utilized, it is judged that it can be fully utilized in a number of processes, including not only the composition of the combinations, but also the analysis of the effect of combinations. It is deemed that it can be fully utilized as a reference in the revision of the flood defense measures establishment process.

Author Contributions: This research was carried out in collaboration among all authors. H.S.K. and K.K. had the original idea and led the research; D.H., J.K., and D.K. performed the data processing and anlaysis and; W.W. and J.J. edited the final manuscript. All authors reviewed and approved the manuscript.

Funding: This work was supported by Korea Environmet Industry \& Technology Institute (KEITI) through Advanced Water Management Research Program, funded by Korea Ministry of Environment (MOE) (83067).

Conflicts of Interest: The authors declare no conflict of interest.

\section{References}

1. Kim, D.H.; Han, D.G.; Kim, H.S. Case study: Prospect of Continuous Rainfall on the Korean Peninsula. Water Future 2018, 51, 38-51.

2. Chen, S.; Hou, Z. Multicriteria Decision Making for Flood Control Operation: Theory and Application. J. Am. Water Resour. Assoc. 2004, 40,67-76. [CrossRef]

3. Yi, C.S.; Lee, S.C.; Kim, H.S.; Shim, M.P. Multicriteria Decision Making Model for Flood Control Project 2. Selection of Most Preferable Alternative and Determination of Investment Priorities. KSCE J. Civ. Eng. 2005, 25, 347-354.

4. De Nocker, L.; Broekx, S.; Liekens, I.; Bulckaen, D.; Smets, S.; Gauderis, J.; Dauwe, W. Cost-benefit analysis to select the optimal flood protection strategy along the Scheldt. Risk Anal. 2006, 1, 271-277. [CrossRef]

5. Levy, J.K.; Hartmann, J.; Li, K.W.; An, Y.; Asgary, A. Multi-Criteria Decision Support System for Flood Hazard Mitigation and Emergency Response in Urban Watersheds. J. Am. Water Resour. Assoc. 2007, 43, 346-358. [CrossRef]

6. Gupta, K. Urban Flood Resilience Planning and Management and Lessons for the Futrue: A Case study of Mumbai, India. Urban Water J. 2007, 4, 183-194. [CrossRef]

7. Byeon, S.H.; Kang, H.J.; Han, J.W.; Kim, T.W. Flood Mitigation Planning for a Basin Using a Decision Tree Model. Ksce J. Civ. Eng. 2008, 28, 33-40.

8. Lee, J.H.; Jun, Y.J.; Ahn, J.H.; Kim, T.W. A Method for Selecting a Structural Optimal Flood Mitigation Plan Using Analytic Hierarchy Process. J. Korean Soc. Hazard Mitig. 2009, 9, 117-126.

9. Heidari, A. Structural master plan of flood mitigation measures. Nat. Hazards Earth Syst. Sci. 2009, 9, 61-75. [CrossRef]

10. Yeo, K.D.; Kim, G.H.; Lee, S.W.; Choi, S.G. Development of MCDM for the Selection of Preferable Alternative and Determination of Investment Priority in Water Resource Projects. KSCE J. Civ. Eng. 2011, 31, 551-563. [CrossRef]

11. Zhou, Q.; Lambert, J.H.; Karvetski, C.W.; Keisler, J.M.; Linkov, I. Flood Protection Diversification to Reduce Probabilities of Extreme Losses. Risk Anal. 2012, 32, 1-15. [CrossRef] [PubMed]

12. Yazdi, J.; Neyshabouri, S.A.A.S.; Niksokhan, M.H.; Sheshangosht, S.; Elmi, M. Optimal prioritization of watershed management measures for flood risk mitigation on a watershed scale. J. Flood Risk Manag. 2013, 6, 372-384. [CrossRef]

13. Alferi, L.; Feyen, L.; Baldassarre, G.D. Increasing Flood Risk under Climate change: A Pan-European assessment of the benefits of four adaptation strategies. Clim. Chang. 2016, 136, 507-521. [CrossRef]

14. Rahman, N.A.; Tarmudi, Z.; Rossody, M.; Muhiddin, F.A. Flood mitigation measures using intuitionistic fuzzy demantel method. Malays. J. Geosci. 2017, 1, 1-15. [CrossRef]

15. Hino, M.; Hall, J.W. Real options analysis of adaptation to changing flood risk: Structural and nonstructural measures. ASCE ASME J. Risk Uncertain. Eng. Syst. Part A Civ. Eng. 2017, 3, 1-12. [CrossRef] 
16. Scionti, F.; Miguez, M.G.; Barbaro, G.; Sousa, M.M.D.; Foti, G.; Canale, C. Integrated Methodology for Urban Flood Risk Mitigation in Cittanova, Italy. J. Water Resour. Plan. Mang. 2018, 144, 1-10. [CrossRef]

17. Tasseff, B.; Bent, R.; Van Hentenryck, P. Optimization of Structural Flood Mitigation Strategies. Water Resour. Res. 2019, 55, 1490-1509. [CrossRef]

18. Ministry of Land, Infrastructure and Transport. The Comprehensive Flood Control Management Plan for Anyangcheon Basin; Ministy of Land, Infrastructure and Transport: Seoul, Korea, 2005.

19. Federal Emergency Management Agency. Revised Guidelines for Implementing Executive Order 11988; Floodplain Management: Nashville, TN, USA, 2015.

20. Official Journal of the European Union. Directive 2007/60/EC of the European Parliament and of the Council of 23 October 2007 on the Assessment and Management of Flood Risks; Official Journal of the European Union: Brussel, Belgium, 2007.

21. Network of Asian River Basin Organizations (NARBO). Flood Management in Japan; Ministry of Land, Infrasture and Transport: Tokyo, Japan, 2015.

22. Penning, R.E.; Peerbolte, B. Floods across Europe: Flood Hazard Assessment, Modelling and Management; Middlesex University Press: London, UK, 1994; pp. 1-17.

23. Petry, B. Coping with Floods: Complementarity of Structural and Non-Structural Measures; Science Press: Beijing, China; New York Ltd.: New York, NY, USA, 2002; pp. 60-70.

24. DJ, P. Systematization of Existing Flood Risk Management Concepts, FLOOD-ERA Working Paper, Flood Hazard Research Centre, Enfield; ERA-Net CRUE: London, UK, 2007.

25. Olfert, A.; Schanze, J. Methodology for Ex-Post Evaluation of Measures and Instruments in Flood Risk Management, FLOODsite Report; FLOODsite: Dresden, Germany, 2007.

26. CRUE. Systematization, Evaluation and Context Conditions of Structural and Non-Structural Measures for Flood Risk Reduction; CRUE Research Report NO I-1; ERA-NET CRUE: London, UK, 2008.

27. Ministry of Land, Infrastructure and Transport. Criteria and Description of River Design; Ministy of Land, Infrastructure and Transport: Seoul, Korea, 2009.

28. Yi, C.S. Decision Making Model for Most Preferable Alternative in Basin-Wide Flood Damage Reduction Planning. Ph.D. Thesis, Inha University, Incheon, Korea, 2005.

29. Zagonari, F.; Rossi, C. A heterogeneous multi-criteria multi-expert decision-support system for scoring combinations of flood mitigation and recovery options. Environ. Model. Softw. 2013, 49, 152-165. [CrossRef]

30. Marcelo, G.M.; Flavio, C.B.M.; de Magalhães, L.P.C.; Carlos, F.V.D. Planning and Design of Urban Flood Control Measures: Assessing Effects Combination. J. Urban Plan. Dev. 2009, 135, 100-109. [CrossRef]

31. Kim, B.S. Selecting of Earth-work Equipment Combination Considered $\mathrm{CO}_{2}$ Emission. Korean Soc. Railw. 2011, 5, 1750-1756.

32. Kim, Y.Y.; Noe, H.S.; Park, T.J. Pump Combination Method of Minimum Specific Energy by Use of Pump Performance Curves. Korean Soc. Fluid Mach. 2010, 2010-2012, 35-39.

(C) 2019 by the authors. Licensee MDPI, Basel, Switzerland. This article is an open access article distributed under the terms and conditions of the Creative Commons Attribution (CC BY) license (http://creativecommons.org/licenses/by/4.0/). 